\title{
Accelerated testing methodology for long-term life prediction of cellulose-based polymeric composite materials
}

\begin{abstract}
This chapter reviews literature concerning reports on the failure mechanisms that are commonly experienced in the techniques that have been developed to predict life expectancy of polymeric composite materials. It summarizes the main degradation mechanisms in polymeric composite materials, techniques used for estimating the life expectancy of polymers, standards for life prediction, and the properties of cellulose-based polymeric composites. The case study demonstrated the effects of incorporating cellulose derived from several resources to the properties of sand-cement block. The compressive strength of sand-cement block incorporated with bacterial cellulose was evaluated for three different periods. Results showed that bacterial cellulose nanofibers enhance the durability of bricks by increasing their compressive strength up to $27 \%$ and reducing the permeability and density of the sand-cement block. In conclusion, accelerated methodology is useful as a potential tool or vehicle for shelf life prediction of composite polymeric materials.
\end{abstract}

Keyword: Accelerated method; Biocement composites; Durability; Polymeric materials; Shelf life prediction 